\title{
Morphology of blends of self-assembling long-chain carbamate and stearic acid*
}

\author{
M. Moniruzzaman and P. R. Sundararajan ${ }^{\ddagger}$ \\ Department of Chemistry, Carleton University, 1125 Colonel By Drive, Ottawa, \\ Ontario K1S 5B6, Canada
}

\begin{abstract}
The morphology of blends of two types of hydrogen-bonding systems was studied with a view to understanding the effect of blending on the extent of hydrogen bonding and changes in the morphology. One of them is the long-chain carbamate with a $\mathrm{C}_{18}$ alkyl side chain, and the other is stearic acid, which also has a $\mathrm{C}_{17}$ alkyl chain. At low concentrations, the $\mathrm{C}_{18}$ carbamate reduces the size of the crystals of stearic acid. However, the stearic acid has no effect on the morphology of the carbamate. The morphological changes are due to the disruptive packing of the alkyl chains, rather than a change in the extent of hydrogen bonding. The blends of homologous carbamates studied before [Moniruzzaman, Goodbrand, Sundararajan, J. Phys. Chem. Part B 107, 8416 (2003)] are more effective in mutually controlling the spherulite size and imparting transparency than the carbamate/stearic acid blend. The presence of the carbamate as the minor component changes the ratio of the intensities of the X-ray reflections at $2 \theta=21.6$ and $2.21^{\circ}$. It is found that in the blends with the carbamates quenched from the melt, the stearic acid exhibits a polymorphic transition from the $\mathrm{E}$ to the $\mathrm{C}$ form in the differential scanning calorimetry (DSC) analysis.
\end{abstract}

\section{INTRODUCTION}

Carbamates are the analog of a hard segment of polyurethanes. They have proven useful in understanding some catalytic processes and the kinetics of the reactions accompanying the polyurethane synthesis process [1,2]. The association process in carbamates is similar to the biological self-assembly (e.g., protein molecules) involving hydrogen bonding. Because of the presence of the polar urethane group (-NH-CO-O-), they can be considered as model compounds for high-molecular-weight polyurethanes having the structural formula $\left(-\mathrm{NH}-\mathrm{CO}-\mathrm{O}-\mathrm{R}_{1}-\mathrm{O}-\mathrm{CO}-\mathrm{NH}-\mathrm{R}_{2}-\right)_{n}$.

In a previous study [3], we synthesized some carbamates with alkyl side chains of different lengths from $\mathrm{C}_{4}$ to $\mathrm{C}_{18}$ and investigated their morphology and thermal behavior. We found that the length of the alkyl side chain of the carbamates has an influence on the morphology, heat of fusion, crystallinity, and crystallite size. Most of the long-chain carbamates exhibit spherulitic morphology, with the size of the spherulites increasing with the length of the alkyl side chain. Progressive fibrillation is seen as the length of the alkyl side chain increases. Most of the carbamates exhibit negative birefringence, indicating the tangential orientation of the molecule within the spherulite. While the melting point increases linearly, the heat of fusion and crystallinity shows a sigmoidal trend.

The melt viscosity of these carbamates is of the order of a few centipoises, and they crystallize rapidly. Because of the long alkyl chain, these carbamates are semicrystalline. Due to these properties, they have potential applications as vehicles in reprography and inkjet printing technologies [4-7]. In

\footnotetext{
*Lecture presented at the symposium "Controlling the self assembly in macromolecular systems: From nature to chemistry to functional properties", as part of the $39^{\text {th }}$ IUPAC Congress and $86^{\text {th }}$ Conference of the Canadian Society for Chemistry: Chemistry at the Interfaces, Ottawa, Canada, 10-15 August 2003. Other Congress presentations are published in this issue, pp. 1295-1603.

¥Corresponding author: E-mail: Sundar@carleton.ca
} 
such applications, the crystalline morphology of the vehicle is an important attribute. If it forms large spherulites during solidification from the melt, it will lead to hazy and brittle prints, whereas small crystallites will impart transparency.

While plasticizers or clarifiers are usually used to modify the crystalline morphology of materials, we examined the possibility of effecting similar changes by blending any two types of carbamates [3]. The difference between the use of the clarifiers and the blends in our previous study is that the latter involves a homologous series of molecules, and both components are capable of hydrogen bonding. It was found that although both the heat of fusion and crystallinity decrease initially with the addition of the second component, they recover beyond a certain composition. The spherulite size also decreases significantly, enhancing the transparency of the sample. An interesting conclusion was that the extent of hydrogen bonding was not affected by blending, and that the changes in morphology were due mainly to the packing of the alkyl chains.

In this paper, we discuss the changes in the morphology of blends of a carbamate with another hydrogen-bonded system. A comparison between these and the blends in our previous study could provide a molecular basis of the relative efficiency of the blends in controlling the morphology.

The carbamate used for this study was $N$-octadecylcarbamate octadecyl ester having the molecular formula $\mathrm{C}_{18} \mathrm{H}_{37}(\mathrm{NHCOO}) \mathrm{C}_{18} \mathrm{H}_{37}$. This carbamate was blended with stearic acid $\left(\mathrm{C}_{17} \mathrm{H}_{35} \mathrm{COOH}\right)$. Henceforth, this carbamate and the stearic acid will be referred to as $\mathrm{C}_{18}$ and SA, respectively. These are shown in Scheme 1.

\section{Scheme 1}
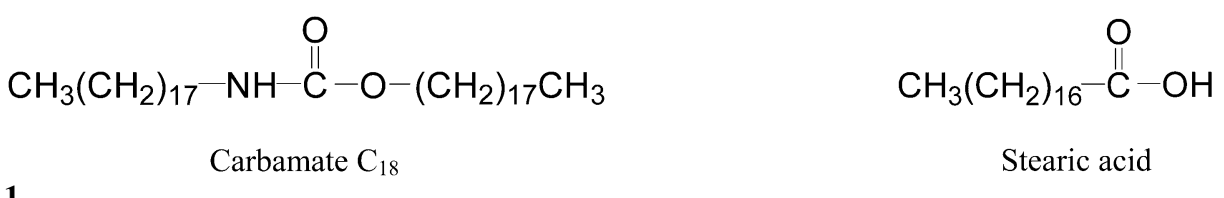

Stearic acid

With the carbamates, the hydrogen-bondable group is symmetrically positioned between the alkyl chain $\mathrm{C}_{18}$ on either side. On the other hand, it forms the head group in SA.

There are four known polymorphic forms of stearic acid: A, B, C, and E. The A, B, and E forms occur only by solution crystallization, whereas the $\mathrm{C}$ form is formed by both solution and melt crystallization [8]. The A form is rare and unstable, whereas the B form is stable at room temperature [9]. The $\mathrm{C}$ polymorph is considered to be the most stable because both $\mathrm{A}$ and $\mathrm{B}$ undergo solid-state phase transition to $\mathrm{C}$ upon heating [10]. The $\mathrm{E}$ form is metastable and transforms to the $\mathrm{B}$ and $\mathrm{C}$ forms through solid-state phase transition under certain conditions [11,12].

There are some structural similarities between the carbamate $\mathrm{C}_{18}$ and the stearic acid. Both of these compounds contain a long alkyl chain and carbonyl group. The intermolecular H-bond exists in both. The single crystal structure of the carbamate $\mathrm{C}_{18}$ is not available. However, some similarities could be derived from the powder X-ray data and the molecular modeling of $\mathrm{C}_{18}$. X-ray diffraction shows that the long spacing for stearic acid $\mathrm{C}$ form is $39.5 \AA$ [13]; in $\mathrm{C}_{18}$ the long spacing is $38.1 \AA$. The length of the $c$ axis of the unit cell of stearic acid $C$ form is $46.6 \AA$, which is equal to the length of two molecules. Molecular modeling shows that the length of one molecule of $\mathrm{C}_{18}$ is $47.99 \AA$ and the $\mathrm{X}$-ray diffractogram of $\mathrm{C}_{18}$ shows a medium intensity peak at $d=46.4 \AA$. Because of the similarities in alkyl moiety and the long spacing of these two H-bonded systems, we studied the morphology of the blends of these, to examine if the crystalline morphology and the extent of hydrogen bonding are affected. When used in the printing process, naturally the melt will be quenched upon transfer to the substrate. Hence, the differences in morphology behavior between samples slowly cooled and quenched from the melt were also investigated in this study. 


\section{EXPERIMENTAL}

The synthesis and purification procedure of the carbamate was described before [3]. Stearic acid of $98+\%$ purity was purchased from Aldrich.

\section{Preparation of blends}

Binary blends of SA and $\mathrm{C}_{18}$ were prepared by melt mixing, with 90/10, 80/20, 70/30, 60/40, 50/50, $30 / 70$, and 10/90 (wt\%) compositions. Preweighed mixtures of SA and $\mathrm{C}_{18}$ were heated in a $10-\mathrm{ml}$ beaker at $110{ }^{\circ} \mathrm{C}$ with continuous stirring. After $1 \mathrm{~h}$, the melt was slowly cooled to room temperature.

\section{Methods for structure and morphology}

Thermal analysis was performed using a DuPont 910 differential scanning calorimeter (DSC) at a heating rate of $10{ }^{\circ} \mathrm{C} / \mathrm{min}$. The instrument was calibrated for temperature and energy with indium and tin reference samples. DSC traces were recorded with about 7-10 $\mathrm{mg}$ of sample, in a nitrogen atmosphere.

$X$-ray diffraction data were collected within the range of $2^{\circ} \leq 2 \theta \leq 50^{\circ}$ using a Philips automated powder diffractometer (model PW 1710) and nickel-filtered $\mathrm{Cu} \mathrm{K}$ radiation $(\lambda=1.542 \AA$ ). The possible presence of texture was checked by taking additional diffractograms with samples turned in the plane of measurement by $90^{\circ}$. The MDI Datascan 3.2 software (Materials Data Inc., Livermore, CA) was used for data collection. The results were analyzed using MDI Jade 5.0 XRD pattern processing software.

The optical micrographs were recorded using a Zeiss Axioplan polarized optical microscope (OM), equipped with a Linkam hot stage. Northern Eclipse (version 6.0) image processing software was used to capture the images, as well as to calculate the spherulite/crystal size. The samples for the optical microscopy were prepared by melting a small amount of the material on the microscope slide at a temperature $20^{\circ} \mathrm{C}$ higher than its melting point, holding it isothermally for $10 \mathrm{~min}$ to remove any morphological history and then cooling it down slowly to room temperature at the rate of $10{ }^{\circ} \mathrm{C} / \mathrm{min}$. Another set of samples was prepared following the same procedure, but in this case, the samples were quenched from the melt, instead of slow cooling.

FTIR spectroscopic measurements were carried out at ambient conditions using a Michelson M129 BOMEM Fourier transform infrared (FTIR) spectrometer. The data were collected using BOMEM GRAMS/386 software for latter evaluation. The sample $(5 \mathrm{mg})$ was sandwiched between two $\mathrm{NaCl}$ disks, melted at $110^{\circ} \mathrm{C}$, and then either slow-cooled or quenched. A background FTIR spectrum was taken for each experiment with the identical sample holder.

\section{RESULTS AND DISCUSSION}

\section{Optical microscopy}

Figure 1 shows the optical micrographs of $\mathrm{C}_{18}$ and SA. The slow-cooled and the quenched samples of $\mathrm{C}_{18}$ show fibrillar spherulites (Figs. 1a and $1 \mathrm{~b}$ ). The average radii of the spherulites of the slow-cooled and quenched samples of $\mathrm{C}_{18}$ are 1170 and $220 \mu \mathrm{m}$, respectively. The slow-cooled and quenched samples of stearic acid show very large crystals (Figs. 1c and 1d), which can be easily seen with the naked eye. Compared to $\mathrm{C}_{18}$, the SA sample was more opaque when it was cooled from the melt on the microscope slide. 

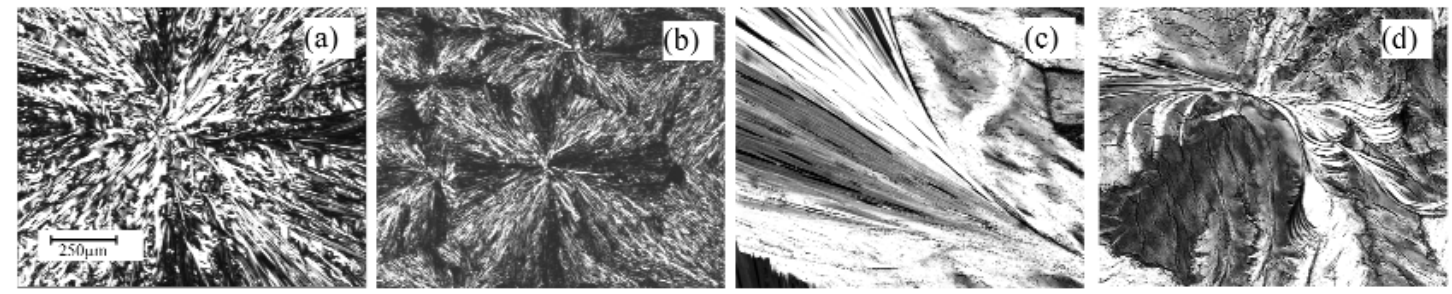

Fig. 1 Optical micrographs of $\mathrm{C}_{18}$ (a and b) and SA (c and d). (a) and (c): slow-cooled; (b) and (d): quenched.

The optical micrographs for the slow-cooled and quenched blends show similar trends in morphology except for the fact that the spherulite/crystal size of the slow-cooled samples is much larger than that of quenched samples. The micrographs of the quenched blends (Fig. 2), show that an addition of 10 to $50 \% \mathrm{SA}$ to $\mathrm{C}_{18}$ causes phase separation, disrupted spherulites of $\mathrm{C}_{18}$ and the crystals of stearic acid are clearly visible under the optical microscope. There was no improvement in the transparency of the samples compared to that of pure $\mathrm{C}_{18}$. When the carbamate is the minor component in the blend, there is a significant reduction of the crystal size as compared to that of pure SA (compare Figs. 1d and 2f). Compared to pure stearic acid, these blends provide better transparency. Thus, it would seem that the carbamate is effective in improving the morphology (e.g., the transparency) of the stearic acid rather than vice versa.
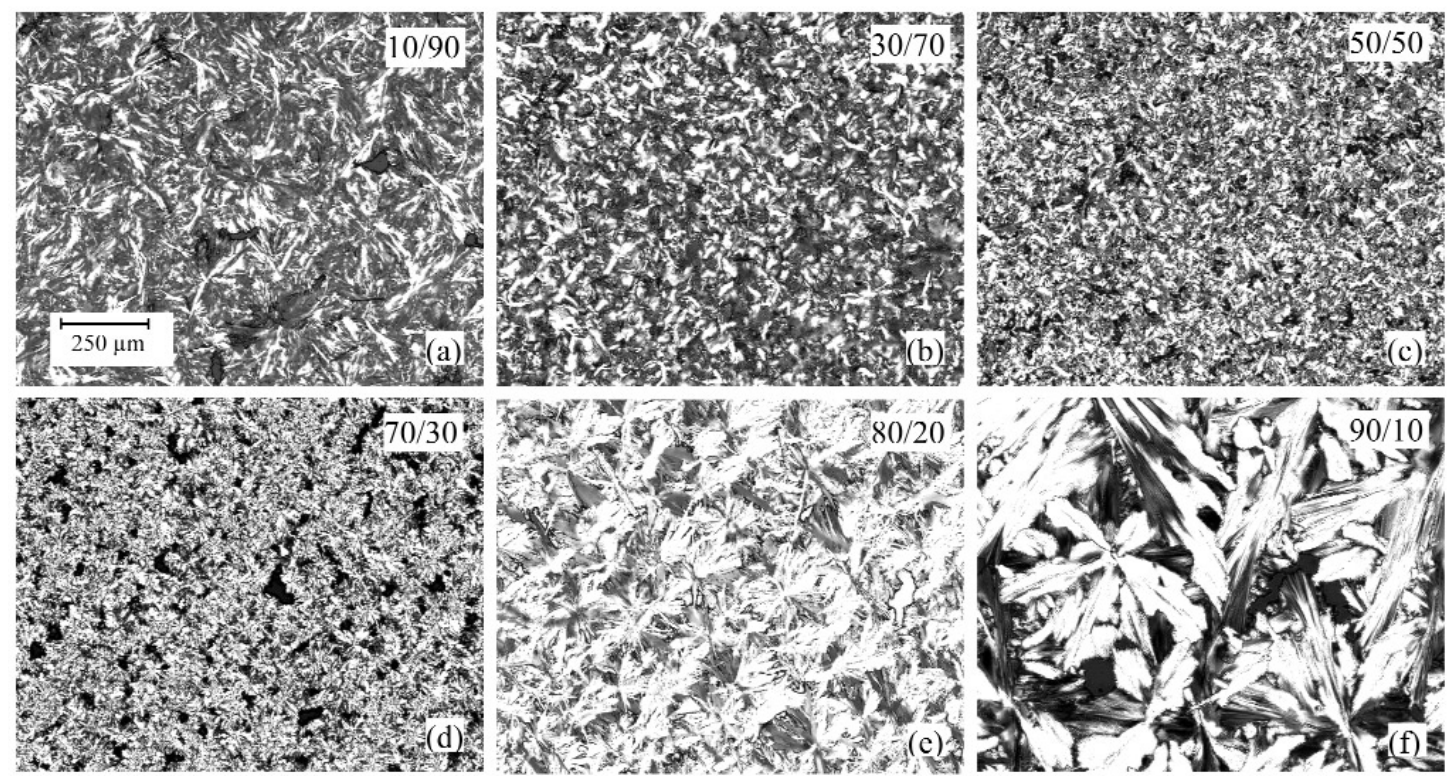

Fig. 2 Optical micrographs of $\mathrm{SA} / \mathrm{C}_{18}$ blends. All the samples were quenched from the melt.

A comparison of the morphology and transparency of these blends with those prepared with the homologous carbamates [3] shows that the latter is more effective in reducing the spherulite size and enhancing the transparency. At some compositions, the spherulite size was reduced to a few microns. 


\section{Thermal analysis}

The melting points obtained from DSC for the slow-cooled and quenched samples of SA and $\mathrm{C}_{18}$ as well as of their blends are shown in Table 1. The melting points of the slow-cooled and quenched samples did not differ significantly. Although the melting point of $\mathrm{C}_{18}$ is higher than that of $\mathrm{SA}$ by about $17^{\circ}$, the $90 / 10,80 / 20,70 / 30$, and $60 / 40$ compositions of SA/C ${ }_{18}$ exhibit single peak in DSC for both the slow-cooled and quenched blends. The 50/50 composition shows a single peak with a shoulder, whereas the 30/70 and 10/90 compositions show two peaks. The melting points of these blends show trends similar to that discussed previously [3] for the blends of $\mathrm{C}_{12}$ and $\mathrm{C}_{16}$ carbamates (here, the subscripts denote the number of carbons in the alkyl side chain of the carbamates). The melting points of 90/10, $80 / 20,70 / 30$, and $60 / 40$ blends are lower than those of either of the parent compounds. In the DSC thermograms of $30 / 70$ and $10 / 90$ composition of $\mathrm{SA} / \mathrm{C}_{18}$, which exhibit two melting peaks, the first melting point is lower than that of pure SA and the second one is lower than that of pure $\mathrm{C}_{18}$. As the fraction of SA decreases in the blend, the temperature corresponding to the second melting point increases, whereas that of the first melting point decreases. In our previous study [3], we observed this type of melting behavior with several series of blend compositions and concluded that such a behavior is due to the components of the blends exerting a mutual plasticizer effect, thereby reducing the melting temperatures.

Table 1 Melting point(s) of $\mathrm{SA} / \mathrm{C}_{18}$ blends.

\begin{tabular}{lccc}
\hline Wt \% of $\mathrm{C}_{18}$ & Slow-cooled sample & \multicolumn{2}{c}{ Quenched sample } \\
\cline { 2 - 4 } & Melting point(s) $\left({ }^{\circ} \mathrm{C}\right)$ & Melting point(s) $\left({ }^{\circ} \mathrm{C}\right)$ & Hump position $\left({ }^{\circ} \mathrm{C}\right)$ \\
\hline 0 & 69.9 & 69.9 & - \\
10 & 68.4 & 68.7 & 61.6 \\
20 & 67.6 & 67.4 & 61.8 \\
30 & 67.4 & 67.2 & 59.8 \\
40 & 67.3 & 66.8 & $58.6 \& 60.7$ \\
50 & 66.8 & 66.8 & 60.5 \\
70 & $66.1 \& 77.3$ & $65.5 \& 77.2$ & 61 \\
90 & $64.5 \& 82.2$ & $64.2 \& 82.4$ & - \\
100 & 86.7 & 86.7 & - \\
\hline
\end{tabular}

An interesting difference between the DSC thermograms of the slow-cooled and quenched blends of SA/C 18 is the appearance of a hump in the latter. Figure 3 shows the DSC thermograms of the slowcooled and quenched samples of the $80 / 20$ blend of $S A / C_{18}$. All the quenched blends, except with the $10 / 90$ and 90/10 compositions, show a hump in DSC thermograms at about $61{ }^{\circ} \mathrm{C}$. Its exact position for different blend compositions is given in Table 1 . This is an indication of a solid-solid transition between polymorphic forms [14]. Interestingly, the thermogram of the quenched sample of stearic acid does not show any hump, which indicates the possibility that the quenched stearic acid is not in the same polymorphic form as in the quenched blends, i.e., the carbamate is inducing a polymorphic transition in the quenched samples. To determine the effect of the heating rate on the position of the hump, the 80/20 blend was run at the heating rate of $2.5^{\circ} \mathrm{C} / \mathrm{min}$. It did not affect the position of the hump significantly (a small change from 61.8 to $61.3^{\circ} \mathrm{C}$ ), whereas the melting peak shifted from 67.4 to $65.3^{\circ} \mathrm{C}$. The identity of the polymorphic form in the quenched blends will be discussed below in the X-ray and infrared analysis sections. 


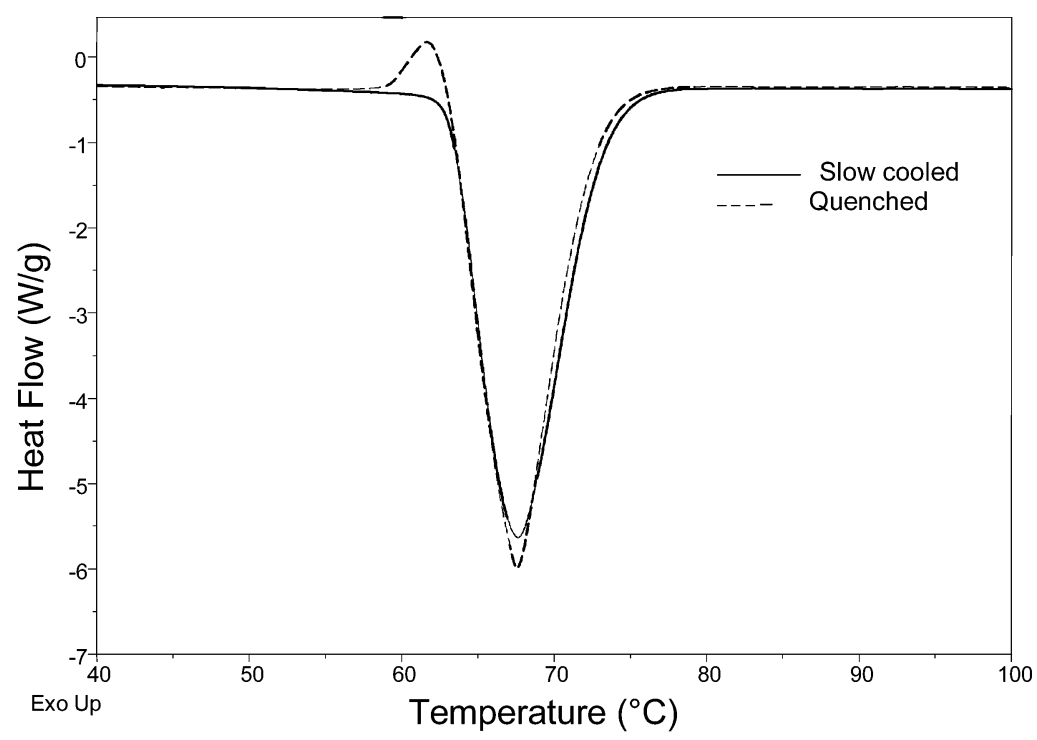

Fig. 3 DSC thermograms of slow-cooled and quenched blends of SA/C 18 with 80/20 composition.

Figure 4 shows the heat of fusion of the slow-cooled samples as a function of the blend composition for the $\mathrm{SA} / \mathrm{C}_{18}$ blend system. For comparison, the heat of fusion for the slow-cooled samples of $\mathrm{C}_{12} / \mathrm{C}_{16}$ blend system is also shown in the same figure. For the $\mathrm{C}_{12} / \mathrm{C}_{16}$ blend, there is initially a decrease in the heat of fusion with the incorporation of $\mathrm{C}_{16}$ in the blend. It passes through a plateau and then increases with an increase in the content of $\mathrm{C}_{16}$. For the $\mathrm{SA} / \mathrm{C}_{18}$ blend system, the heat of fusion decreases up to $30 \%$ of $\mathrm{C}_{18}$ in the blend. There is then an increase with $40 \%$ of $\mathrm{C}_{18}$, with no further change with an increase in the $\mathrm{C}_{18}$ content. Thus, when $\mathrm{C}_{18}$ is the minor component, there is a change

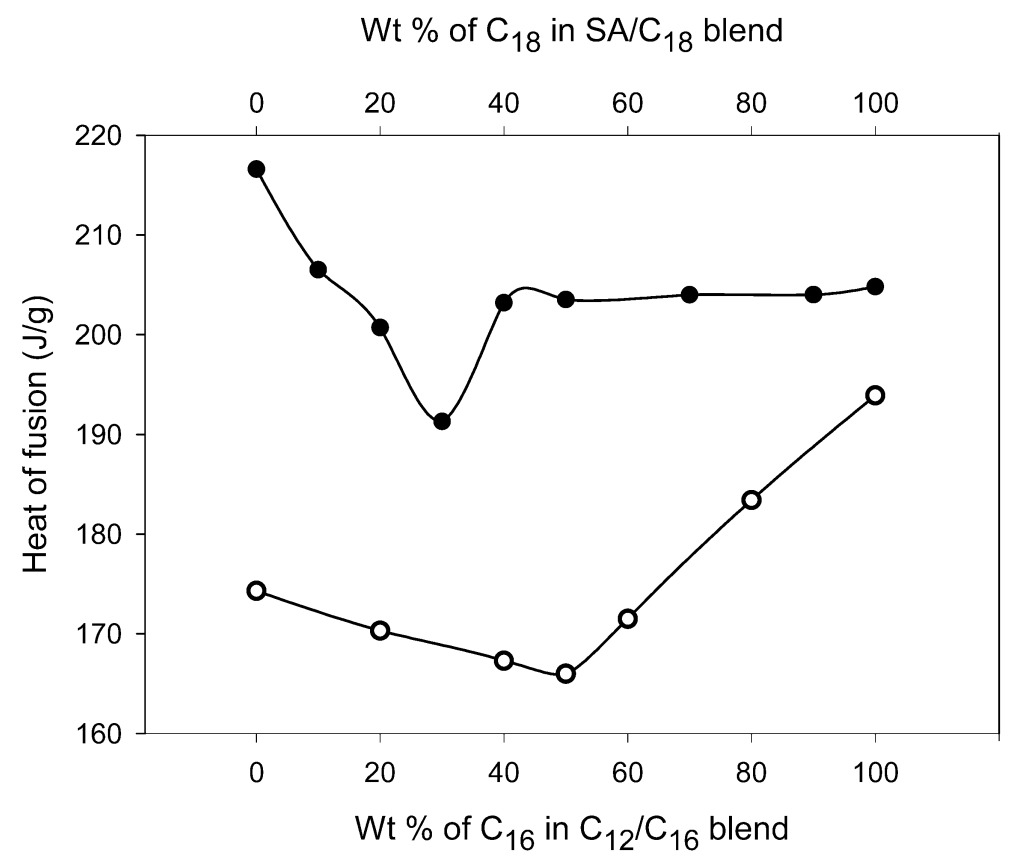

Fig. 4 Heat of fusion of slow-cooled blends of $\mathrm{SA} / \mathrm{C}_{18}(-\bullet)$ and $\mathrm{C}_{12} / \mathrm{C}_{16}(-\circ)$. 
in the crystallinity and morphology. The SA, as a minor component, does not cause any change in the morphology of the carbamate. Owing to the hump in the DSC thermograms of the quenched blends, the heat of fusion could not be calculated reliably, and hence they are not shown in Fig. 4.

\section{X-ray diffraction}

X-ray powder diffractograms of the slow-cooled samples of SA and $\mathrm{C}_{18}$ are shown in Figs. 5a and 5b respectively. Comparison of the powder diffraction pattern of SA with the published X-ray pattern of different polymorphic forms of stearic acid [15] indicates that it is in the $\mathrm{C}$ form in both the slow-cooled and the quenched samples. From Fig. 5, it is seen that some of the reflections from SA and $\mathrm{C}_{18}$ occur at about the same $2 \theta$, due to the similarity of the long spacing and the subcell structures mentioned in the Introduction.

The X-ray diffractograms of the blends do not show any new reflection as compared to those from $\mathrm{SA}$ and $\mathrm{C}_{18}$. However, some close reflections from $\mathrm{SA}$ and $\mathrm{C}_{18}$ merge and show single peak in the blend. For example, the reflection at $2 \theta=6.60^{\circ}(d=13.38 \AA)$ from SA and the reflection at $2 \theta=7.03^{\circ}$ $(d=12.56 \AA)$ from $\mathrm{C}_{18}$ merges in the $50 / 50$ blend and shows a reflection at $2 \theta=6.57^{\circ}(d=13.45 \AA)$. The diffractograms of the slow-cooled blends indicate that the stearic acid is still in $\mathrm{C}$ form in the blends.
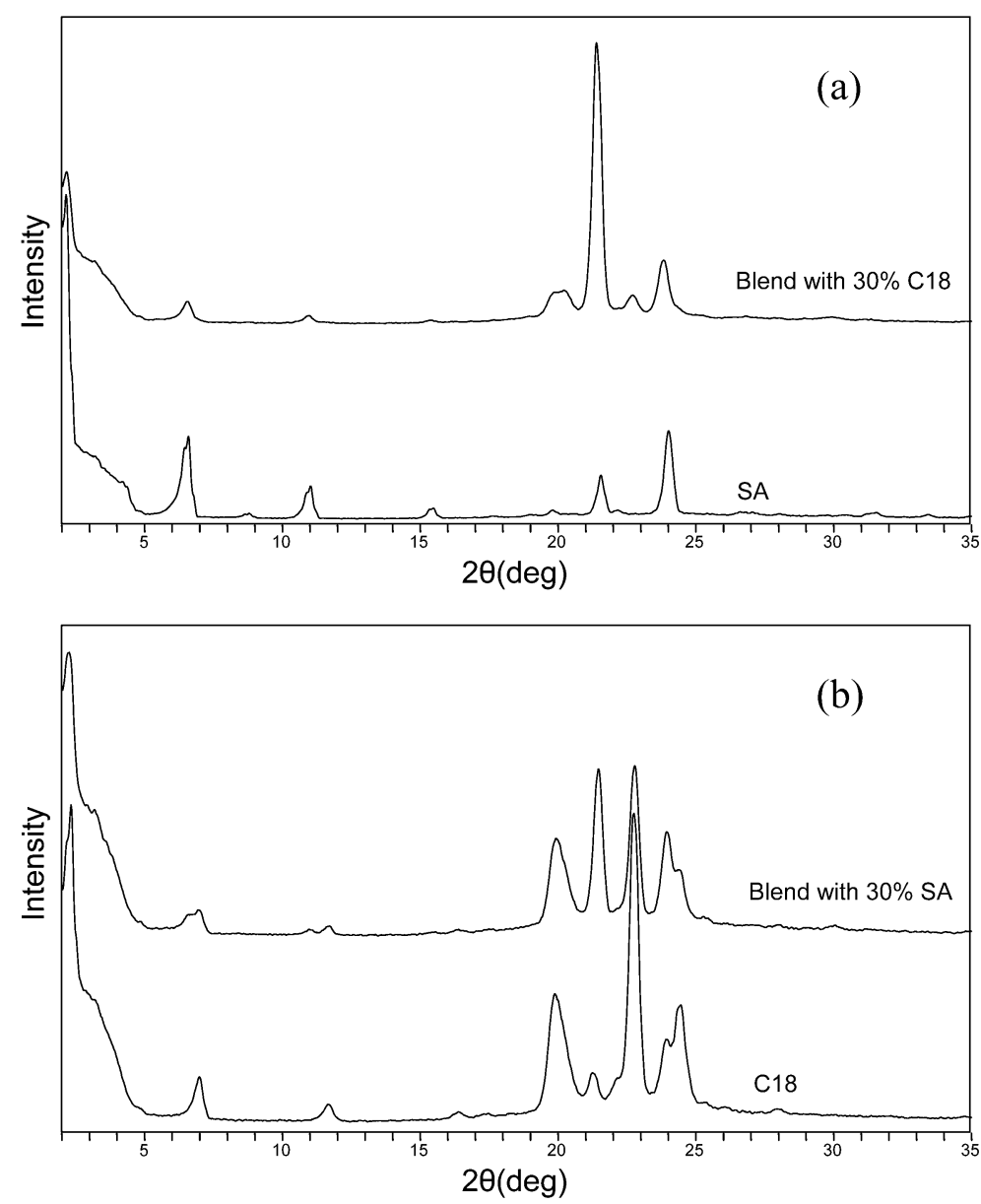

Fig. 5 X-ray diffractograms of (a) SA and its blend with $30 \% \mathrm{C}_{18}$ (b) $\mathrm{C}_{18}$ and its blends with $30 \% \mathrm{SA}$. All the samples are slowly cooled. 
The relative intensities of the reflections from the slow-cooled and quenched blends were found to be different. As mentioned earlier, the DSC thermograms of the quenched blends indicate the presence of a metastable polymorphic form of stearic acid. The $d$-spacings of the A form of stearic acid are significantly different from those of the $\mathrm{C}$ form [15]. The diffractograms indicate that the stearic acid is not in the A form in the quenched blends. This is also supported by the IR spectra, which will be discussed below. However, it cannot be decided unambiguously from the powder diffraction patterns whether stearic acid is in the B or E form in the quenched blends. This is due to the long spacings of the two forms being nearly equal that they could not be distinguished by X-ray diffraction. In addition, the presence of $\mathrm{C}_{18}$ in the blends further complicates the situation, since some reflections from $\mathrm{C}_{18}$ merge with those of SA in the blends. However, IR spectra can help us to identify this polymorph.

The diffractograms of the blends show some interesting features. Figure 5a shows the X-ray diffractogram of the slow-cooled blend, containing $30 \% \mathrm{C}_{18}$ along with the diffractogram of pure SA. It is seen that the addition of $30 \% \mathrm{C}_{18}$ to stearic acid causes a major change in the diffractogram. There is a significant increase in the intensity at $2 \theta=21.6^{\circ}(d=4.1 \AA)$ and a decrease in the intensity at $2 \theta=2.21^{\circ}(d=40 \AA)$. Figure 6 shows the intensity ratio of these two reflections for the slow-cooled and quenched blends as well as the pure components. It is seen that the intensity ratio changes significantly when $\mathrm{C}_{18}$ is the minor component in the blend. For the slow-cooled samples, the maximum change is observed at 70/30 composition of $\mathrm{SA} / \mathrm{C}_{18}$, whereas in the quenched sample, the maximum change is observed at 90/10 composition. Figure 5 b shows that when SA is the minor component in the blend, there is no major change in the diffractogram as compared to that of pure $\mathrm{C}_{18}$, and that the diffractogram is just a combination of the diffractograms of $\mathrm{SA}$ and $\mathrm{C}_{18}$.

In the crystal structure of stearic acid, the $d$-spacings of 40.0 and $4.1 \AA$ correspond to [001] and the [110] planes, respectively [11]. Further, in stearic acid, the intensity at $d=4.1 \AA$ is very low compared to that of the $40 \AA$ reflection, for both the slow-cooled and quenched samples. Reduction of intensity of the long spacing of stearic acid in the blends indicates that $\mathrm{C}_{18}$ disturbs the crystal lattice of stearic acid to some extent. However, none of the pure polymorphs of stearic acid exhibit such a strong reflection at $d=4.1 \AA$, as is observed in case of the blends of this study. Frede et al. [16] observed a similar decrease in intensity at $40 \AA$ and increase in intensity at $4.1 \AA$ when they melt blended stearic

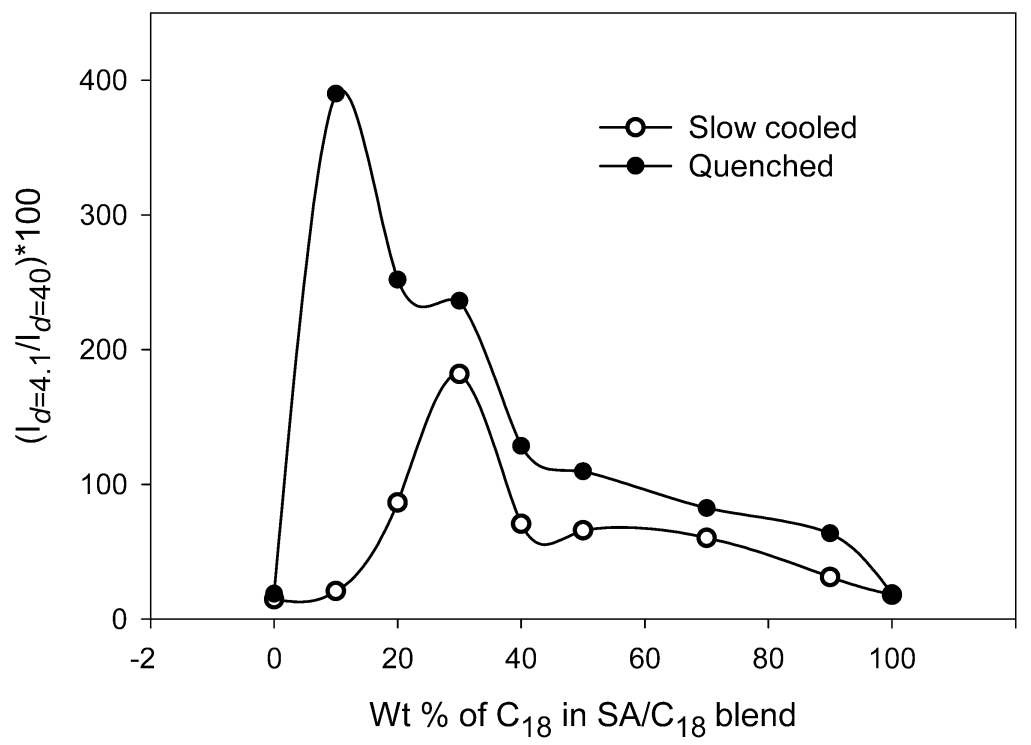

Fig. 6 Intensity ratio of the diffraction maxima at $d=4.1 \AA$ and $40 \AA$ for the slow-cooled and quenched blends. 
acid with palmitic acid. However, they did not report the polymorphic transition observed in this study with the blends.

\section{IR analysis}

Figure 7 shows the infrared spectra of pure SA and $\mathrm{C}_{18}$ and that of the $50 / 50$ blend. No new peak appears in the spectrum of the blends as compared to pure $\mathrm{SA}$ and $\mathrm{C}_{18}$. The carbonyl stretching frequency for $\mathrm{SA}$ and $\mathrm{C}_{18}$ is 1702 and $1686 \mathrm{~cm}^{-1}$, respectively. In the blends, only one $-\mathrm{C}=\mathrm{O}$ stretching is seen at about $1698 \mathrm{~cm}^{-1}$ in both the slow-cooled and quenched samples. At first glance this indicates the possibility that an interaction between the components in the blends has affected the type of hydrogen bonding of the system. However, the $\mathrm{C}=\mathrm{O}$ band of $\mathrm{C}_{18}$ is so close to that of stearic acid that even a physical mixing would lead to an apparently single band due to superposition. To this end, we made a 50/50 physical mixture of SA and $\mathrm{C}_{18}$ and recorded its IR spectrum with a $\mathrm{KBr}$ pellet. This spectrum was compared with the spectra of the slow-cooled and quenched blends of the 50/50 composition that were also taken with a $\mathrm{KBr}$ pellet. Only one $-\mathrm{C}=\mathrm{O}$ absorption peak was observed in all the three samples, having similar stretching frequency. Thus, the single $\mathrm{C}=\mathrm{O}$ stretching band in the blends might not necessarily indicate an interaction between the components in the blends. Further analysis of the spectra shows that there is no shift in the $-\mathrm{NH}$ stretching frequency of $\mathrm{C}_{18}\left(\right.$ at $3341 \mathrm{~cm}^{-1}$ ) in any of the blends. Even then, we cannot rule out the possibility of the presence of $\mathrm{H}$-bonds between $\mathrm{C}_{18}$ and the stearic acid in the blends because these H-bonds still involve a carbonyl group so that no significant shift should be expected. Since the unit cells in stearic acid are connected through intermolecular H-bonding between $\mathrm{C}=\mathrm{O}$ and $\mathrm{OH}$ groups of stearic acid, any $\mathrm{H}$-bond between $\mathrm{C}_{18}$ and stearic acid in the blends should result in disruption of the crystal lattice of stearic acid to some extent. This is supported by the decrease in the intensity of the long spacing $(d=40 \AA)$ of stearic acid in the blends. It should be mentioned that in our previous study [3] of the blend system of homologous carbamates, the extent of hydrogen bonding is unaffected, and yet those systems exhibit excellent transparency, low crystallinity, and low heat of fusion, which were attributed to the poor packing of the alkyl chains in the blends.

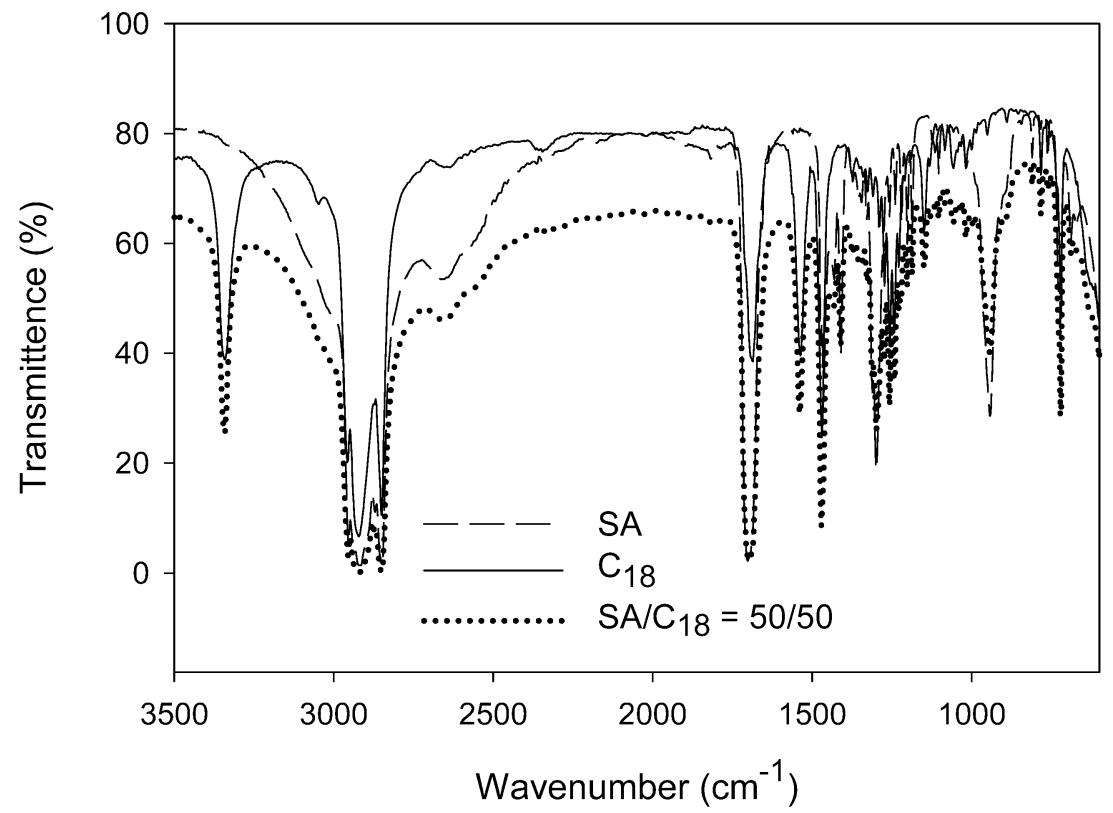

Fig. 7 IR spectrum of SA and $\mathrm{C}_{18}$ and of their 50/50 blend. 
Finally, we tried to get some information from IR spectra regarding the polymorphic forms of stearic acid in the slow-cooled and quenched blends. Holland et al. [17] studied the infrared spectra of single crystals of the four forms of stearic acid. Their study revealed that in the spectrum of the $\mathrm{C}$ form, a band at $689 \mathrm{~cm}^{-1}$ can be attributed to the $\mathrm{O}-\mathrm{C}=\mathrm{O}$ bond angle deformation. For $\mathrm{A}$ and $\mathrm{E}$ forms, this band appears at $677 \mathrm{~cm}^{-1}$ and $686 \mathrm{~cm}^{-1}$, respectively. In the B form, no band was found between 650 and $700 \mathrm{~cm}^{-1}$ indicating that this vibration has considerably lower frequency. In our study, SA and its blends with $\mathrm{C}_{18}$ show a band around $688 \mathrm{~cm}^{-1}$ in both slow-cooled and quenched samples. This observation rules out the possibility of $\mathrm{A}$ and $\mathrm{B}$ polymorphic forms in these blends. Although there are some differences in the single crystal IR spectra of $\mathrm{C}$ and $\mathrm{E}$ forms, the spectra of polycrystalline samples of the $\mathrm{C}$ and $\mathrm{E}$ forms are not very different [17], and hence they are difficult to distinguish. X-ray diffraction, along with the IR spectrum of SA and of slow-cooled blends indicates that stearic acid is in the C form. This is reasonable on the basis of previous studies, which showed that melt-grown SA crystals are usually in the $\mathrm{C}$ form, which is the most stable form [10]. Since the quenched blends show polymorphic transition in DSC and their X-ray and IR spectra are not much different from C form, the only possibility is that the $\mathrm{SA}$ is in the $\mathrm{E}$ form in the quenched blends. The transition from the metastable $\mathrm{E}$ form to $\mathrm{C}$ form on heating has been reported earlier [12].

\section{CONCLUSIONS}

In this study, we found that blending affects the morphology of the carbamate and stearic acid. The spherulites of $\mathrm{C}_{18}$ are disrupted due to blending, and the large crystals of stearic acid transform into tiny crystals. This effect is more pronounced when carbamate is the minor component in the blend. At these compositions, the blends show considerable improvement in transparency. As expected, in all cases, the spherulite/crystal size of the slow-cooled samples is found to be larger than that of the quenched samples. Comparing with our previous study, it seems that blending of two homologous compounds is more efficient than our present blend system in controlling the morphology. The previous system with homologous molecules provided much better transparency.

$\mathrm{SA}$ and $\mathrm{C}_{18}$ exert a mutual diluent effect, resulting in a depression of the melting points. When the carbamate is the minor component in the blend, there is a decrease in the heat of fusion. A decrease in the intensity of long spacing in X-ray diffractograms at these compositions indicates that the crystal lattice is disturbed to some extent due to blending. Thermal analysis reveals that quenching with the carbamate induces polymorphism in stearic acid in the blend. A metastable phase is formed, which is converted to the most stable $\mathrm{C}$ form on heating.

IR analysis shows that the extent of hydrogen bonding is unaffected whether we blend carbamate with another homologous carbamate or with stearic acid. It seems that blending can be an efficient alternative to the conventional clarifiers or plasticizers to control the morphology. Our present study indicates that long-chain carbamates can be used to control the morphology of stearic acid or homologous fatty acids if their application in any specific system requires controlled morphology.

\section{ACKNOWLEDGMENT}

This work was supported by the Natural Sciences and Engineering Research Council of Canada (NSERC) and Xerox Research Centre of Canada (XRCC). M. Moniruzzaman was partly supported by the Ontario Graduate Scholarship for Science and Technology (OGSST). 


\section{REFERENCES}

1. S. Wong and K. C. Frisch. Polym. Mater. Sci. Eng. 50, 480 (1984).

2. T. E. Lipatova, L. A. Bakalo, L. J. Kzirkova. Sint. Fiz.-Khim. Polim. 23, 74 (1978).

3. M. Moniruzzaman, B. Goodbrand, P. Sundararajan. J. Phys. Chem. B 107, 8416-8423 (2003).

4. Jpn. Kokai Tokkyo Koho. JP 58201758 (1983). Chem. Abstr. 100, 174289z.

5. T. Tanaka, T. Yoshitomi, Y. Hanada, M. Ohashi, Y. Takeda. Jpn. Kokai Tokkyo Koho JP 6290 289. Chem. Abstr. 107, 20896 b.

6. B. Goodbrand, D. Boils, P. R Sundararajan, R. Wong, S. Malhotra. U.S. Patent 6,187,082 (2001).

7. B. Goodbrand, D. Boils, P. R Sundararajan, R. W. Wong. U.S. Patent 6,414,051 (2002).

8. F. Kaneko, H. Sakashita, M. Kobayashi. J. Phys. Chem. 98, 3801-3808 (1994).

9. K. Sato and R. Boistelle. J. Cryst. Growth. 66, 441-450 (1984).

10. N. Garti, E. Wellner, S. Sarig. J. Cryst. Growth 57, 577 (1982).

11. F. Kaneko, T. Simofuku, H. Miyamoto, M. Kobayashi. J. Phys. Chem. 96, 10554-10559 (1992).

12. F. Kaneko, M. Kobayashi, Y. Kitagawa, Y. Matsuura. J. Phys. Chem. 96, 7104 (1992).

13. K. Sato and M. Okada. J. Cryst. Growth 42, 259-263 (1977).

14. W. W. Wendlandt. Thermal Analysis, p. 667, Wiley-Interscience, New York (1986).

15. N. Garti, E. Wellner, S. Sarig. Kristall Technik 15, 1303-1310 (1980).

16. E. Frede and D. Precht. J. Am. Oil Chem. Soc. 53, 668-670 (1976).

17. F. Holland and J. R. Nielsen. J. Mol. Spectrosc. 9, 436-440 (1962). 